\title{
Cólera en gestantes en el Hospital Nacional Cayetano Heredia, Lima-Perú.
}

Cholera in pregnant women at the Hospital Nacional Cayetano Heredia, Lima Perú.

\author{
SAONA Pedro ${ }^{1}$, ASTUdillo Javier ${ }^{1}$, FIGUEROA Moises ${ }^{2}$, y MARADIEGUE \\ Eduardo $^{3}$
}

${ }^{1}$ Médico Asistente, Departamento de Obstetricia y Ginecología Hospital Nacional Cayetano Heredia.

${ }^{2}$ Jefe de Servicio. Departamento Obstetricia y Ginecología Hospital Nacional Cayetano Heredia. Profesor Auxiliar, Departamento de Obstetricia y Ginecología. Universidad Peruana Cayetano Heredia

${ }^{3}$ Jefe del Departamento de Obstetricia y Ginecología, Hospital Nacional Cayetano Heredia. Profesor principal, Departamento de Obstetricia y Ginecología. Universidad Peruana Cayetano Heredia.

\section{SUMMARY}

All cases of cholera in pregnant women (84) admitted to Hospital Nacional Cayetano Heredia, Lima-Perú were reviewed from febraury $1^{\text {st }}$ to May $31^{\text {st }}, 1991$. Most of the patients $(90 \%)$ came from shanty towns sorrounding the hospital, their main complain was profuse watery diarrhea and vomiting.

Vibrio cholerae 01 biotype El Tor serotype Inaba was identified as the causative agent. The 84 pregnant women represent less than $1 \%$ of all cholera patients attended at the hospital. Twenty patients requiered hospitalization because of sever dehydration; one developed acute renal failure. The proportion of pregnant women who requiered hospitalization was higher in those less than 20 years old $(50 \%)$. Fetal loss ocurred mainly in young pregnant women $(30 \%)$ and in $1^{\text {nd }}$ trimester patients $(\mathbf{7 \%})$. The treatment was based in oral or intravenous fluid replacement and early administration of antimicrobial agents.

KEY WORDS: Cholera, pregnancy, abortion.

\section{RESUMEN}

Este es un estudio retrospectivo de todos los casos de cólera en gestantes (84) que acudieron al Hospital Nacional Cayetano Heredia entre el $1^{\circ}$ de febrero y el 31 de mayo de 1991. La mayoría de las pacientes provenían de las zonas pobres cercanas al hospital (90\%), presentando diarrea acuosa abundante y vómitos. Se identificó como agente causal al Vibrio cholerae 01 biotipo El Tor serotipo Inaba. Las 84 gestantes representaron menos de $1 \%$ de todos los pacientes atendidos por cólera en el hospital. 
Se hospitalizaron 20 pacientes con cuadros severos de deshidratación, una desarrolló insuficiencia renal aguda.

La proporción de gestantes que requirió internamiento fue mayor en el grupo de menores de 20 años (50\%).

Las pérdidas fetales ocurrieron principalmente en gestantes jóvenes (30\%) y en pacientes en el primer y segundo trimestre (7\%). El tratamiento se basó en rehidratación oral o parenteral y uso de antibióticos tempranamente.

PALABRAS CLAVES: Cólera, gestación, abortos.

\section{INTRODUCCIÓN}

El cólera, enfermedad que produce elevada morbilidad y mortalidad debido a severa deshidratación inducida por vómitos y diarrea, se presenta actualmente en forma endémica en países del sur de Asia (1). La forma epidémica causada generalmente por la cepa El Tor se ha descrito en los últimos años en países de Asia, Europa, África y Pacífico del Sur, no habiéndose reportado en países de Sudamérica (2).

En enero de 1991 se inicia una epidemia en la región norte del Perú, la cual se ha difundido rápidamente a todo el país por la situación de pobreza, inadecuado saneamiento ambiental y deficiente educación sanitaria de la mayor parte de la población urbano marginal y rural (3).

Los primeros casos de cólera se reportaron en nuestro hospital a fines de enero, y los primeros casos de mujeres gestantes llegaron a nuestro servicio en febrero de 1991 .

En los reportes del siglo pasado $(4,6)$, el cólera en la mujer embarazada presentó altas tasas de natimuertos y elevada morbi-mortalidad materna.

Con el advenimiento de los nuevos métodos de hidratación parenteral y posteriormente el concepto de rehidratación oral y uso de antibióticos disminuyó la severidad del cuadro en la madre pero mantiene su efecto sobre la mortalidad perinatal (4).

El presente trabajo se realizó con el objeto de evaluar el impacto de la epidemia actual en la mujer gestante y su producto, atendido en el servicio de gestante y su producto, atendido en el servicio de Obstetricia del Hospital Nacional Cayetano Heredia.

\section{MATERIAL Y MÉTODOS}

Se realizó un estudio retrospectivo descriptivo de las gestantes con cólera que acudieron al Servicio de Emergencia del Hospital Nacional Cayetano Heredia (HNCH) entre el primero de febrero y el 31 de mayo de 1991. Nuestro hospital, ubicado en el denominado cono norte de la ciudad de Lima, brinda atención a una población total aproximada de un millón trescientas mil personas, de las cuales son mujeres en edad reproductiva algo más de $23 \%$ y gestantes el $4,7 \%$.

El diagnóstico se hizo en la mayoría de pacientes en base al cuadro clínico de diarrea líquida profusa, de inicio brusco y curso rápido acompañado de náuseas, vómitos $\mathrm{y}$ calambres abdominales. Se realizó coprocultivo a las primeras pacientes que acudieron 
al hospital con el cuadro clínico descrito, de acuerdo al recomendado por el Ministerio de Salud del Perú $(7,8)$.

Se revisaron las historias de las gestantes con cólera hospitalizadas y las notas de emergencia de las pacientes con tratamiento ambulatorio, con el objeto de evaluar datos generales de filiación, severidad y tratamiento del cólera, presencia de factores epidemiológicos importantes y estado y evolución de la gestación durante la enfermedad.

\section{RESULTADOS}

Durante los meses de febrero a mayo de 1991 se atendieron 8690 pacientes con cólera en el Hospital Nacional Cayetano Heredia, de acuerdo a los informes de su centro de cómputo, de ellos, $84(0.96 \%)$ fueron gestantes. El número de partos hospitalarios fue de 942 siendo la incidencia de gestantes con cólera durante este periodo 8.92 por 100 partos. De las 84 gestantes, $20(23,8 \%)$ necesitaron ser hospitalizadas, lo que representa el $0.44 \%$ de los 4500 pacientes internados por cólera. La mayoría de gestantes $(90 \%)$ provenían de distritos cercanos al hospital (cono norte) y sólo 8 de otros distritos.

De los 84 gestantes atendidas en el hospital con enfermedad diarreica aguda durante la epidemia de cólera se realizaron estudios bacteriológicos en siete, en todos se aisló Vibrio cholerae 01 biotipo E1 Tor serotipo Inaba.

El embarazo terminó durante el episodio de cólera en 8 de las 84 gestantes, 4 a término, 3 en el segundo trimestre y un aborto de 11 semanas. En 5 pacientes $(5,9 \%)$ se obitó el producto, uno a término, y los otros 4 entre las 10 y 26 semanas de gestación.

En el mes de abril se atendió el mayor número de gestantes con cólera (40), y el menor número en febrero (12). Sin embargo el porcentaje de hospitalización más alto $50 \%$ (6/12) fue en febrero y el más bajo $10 \%$ (4/40) en abril (Tabla $\left.\mathrm{N}^{\circ} 1\right)$. La mayor proporción de óbitos $(15,4 \%)$ se registró en mayo (Tabla $\left.\mathrm{N}^{\circ} 2\right)$.

Tabla No 1. Gestantes con cólera. Distribución por necesidad de hospitalización y mes.

\begin{tabular}{|lccc|}
\hline & HOSPITALIZADAS & AMBULATORIAS & TOTAL \\
\hline FEBRERO & 6 & 6 & 12 \\
MARZO & 7 & 12 & 19 \\
ABRIL & 4 & 36 & 40 \\
MAYO & 3 & 10 & 13 \\
& & & \\
\hline
\end{tabular}


Tabla No 2. Gestantes con colera

Distribución de gestantes con obitos por mes

\begin{tabular}{|lccc|}
\hline & CON OBITOS & SIN OBITOS & TOTAL \\
\cline { 2 - 4 } & 1 & 11 & 12 \\
FEBRERO & 0 & 19 & 19 \\
MARZO & 2 & 38 & 40 \\
ABRIL & 2 & 11 & 13 \\
MAYO & & & \\
\hline
\end{tabular}

La edad promedio de las gestantes con cólera fue 25.4 años (SD 5.4) con un rango de 16 a 40 años. El mayor porcentaje de mujeres (67,5\%) tenía entre 20 y 29 años, $20.5 \%$ eran mayores de 30 y 12\% menores de 20 años. De las pacientes menores de 20 años se hospitalizó la mitad (5/10), y sólo hicieron el 19.6\% (11/56 y el 23.5\% (4/17) de las pacientes mayores de 20 y 30 años respectivamente (Tabla $\mathrm{N}^{\circ} 3$ ).

Tabla No 3. Gestantes con colera. Caracteristicas de acuerdo a necesidad de hospitalización

\begin{tabular}{|c|c|c|c|}
\hline & Hospitallzadas & Ambulatorlas & Totel \\
\hline \multicolumn{4}{|l|}{ EDAD } \\
\hline $\begin{array}{l}<19 a \\
20-29 a \\
>30 a\end{array}$ & $\begin{array}{r}5 \\
11 \\
4\end{array}$ & $\begin{array}{r}5 \\
46 \\
13\end{array}$ & $\begin{array}{l}10 \\
56 \\
17\end{array}$ \\
\hline \multicolumn{4}{|l|}{ PARIDAD } \\
\hline $\begin{array}{l}\text { Nulfpera(0) } \\
\text { Multipara(1-3) } \\
\text { Gran multipara(24) }\end{array}$ & $\begin{array}{r}6 \\
12 \\
2\end{array}$ & $\begin{array}{r}22 \\
35 \\
7\end{array}$ & $\begin{array}{r}28 \\
47 \\
9\end{array}$ \\
\hline \multicolumn{4}{|c|}{ TIEMPO DE GE8TACION } \\
\hline $\begin{array}{l}\text { 10 Trimestre } \\
\text { 20 Trimestre } \\
\text { 3o Trimestre }\end{array}$ & $\begin{array}{r}2 \\
11 \\
7\end{array}$ & $\begin{array}{l}11 \\
32 \\
21\end{array}$ & $\begin{array}{l}13 \\
43 \\
28\end{array}$ \\
\hline \multicolumn{4}{|c|}{ TIEMPO DE ENFERMEDAD } \\
\hline $\begin{array}{l}1 \text { dla } \\
2 \text { dias } \\
3 \text { dles }\end{array}$ & $\begin{array}{l}7 \\
6 \\
8\end{array}$ & $\begin{array}{r}10 \\
7 \\
10\end{array}$ & $\begin{array}{l}26 \\
12 \\
18\end{array}$ \\
\hline
\end{tabular}

Hubo 30\% (3/10) de pérdidas fetales en el grupo de gestantes menores de 20 años y $3,7 \%(2 / 56)$ en las mayores de 20 , no se registraron óbitos en las mayores de 30 años (Tabla 4). 
Tabla No 4. Cestantes con oblera. Caracteriaticas

de souerdo a presencia do bbitos

\begin{tabular}{|c|c|c|c|}
\hline & Con obltos & Sin sbltos & Total \\
\hline \multicolumn{4}{|l|}{ EDND } \\
\hline $\begin{array}{l}10 a \\
20-20 a \\
? 30 a\end{array}$ & $\begin{array}{l}3 \\
2 \\
0\end{array}$ & $\begin{array}{l}7 \\
64 \\
17\end{array}$ & $\begin{array}{l}10 \\
58 \\
17\end{array}$ \\
\hline \multicolumn{4}{|l|}{ PARIOND } \\
\hline $\begin{array}{l}\text { Nulppera(0) } \\
\text { Multipara(1-3) } \\
\text { Gren multipara(14) }\end{array}$ & $\begin{array}{l}3 \\
2 \\
0\end{array}$ & $\begin{array}{r}26 \\
46 \\
0\end{array}$ & $\begin{array}{r}28 \\
47 \\
9\end{array}$ \\
\hline \multicolumn{4}{|c|}{ TIEMPO DE OESTACION } \\
\hline $\begin{array}{l}\text { 10 Trimestro } \\
20 \text { Trimeatro } \\
30 \text { Trimeotre }\end{array}$ & $\begin{array}{l}1 \\
\mathbf{3} \\
1\end{array}$ & $\begin{array}{l}12 \\
40 \\
27\end{array}$ & $\begin{array}{l}13 \\
43 \\
28\end{array}$ \\
\hline \multicolumn{4}{|c|}{ TIEMPO DE ENFERMEDAD } \\
\hline $\begin{array}{l}1 \text { dila } \\
2 \text { diae } \\
3 \text { diee }\end{array}$ & $\begin{array}{l}0 \\
2 \\
2\end{array}$ & $\begin{array}{l}20 \\
10 \\
10\end{array}$ & $\begin{array}{l}20 \\
12 \\
18\end{array}$ \\
\hline
\end{tabular}

De las gestantes con cólera 33,3\% eran nulíparas, 56\% eran multíparas, y el 10,7\% grandes multíparas.

El menor porcentaje de hospitalizaciones 21,4\% (6/28) ocurrió en el grupo de nulíparas y el mayor porcentaje 25,5\%(12/47) en las multíparas (tabla 3). El porcentaje de óbitos en el grupo de nulíparas fue $10,7 \%(3 / 28)$ y 4,2\% $(2,47)$ en las multíparas (tabla 4$)$.

El tiempo de gestación promedio en las pacientes con cólera fue 23.7 semanas (SD 9.2) con un rango de 7 a 41 semanas. El 15,5\% de las gestantes estaba en el primer trimestre, $51,2 \%$ en el segundo trimestre y el 33,3\% en el tercer trimestre. Se hospitalizó el 15,4\% $(2 / 13)$ de pacientes en el primer trimestre, y el 25\% de gestantes del segundo (11/43) y tercer trimestre (7/28) (tabla 3). La mayor proporción de pérdidas fetales ocurrieron en el primer y segundo trimestre 7,7\% con intervalo de confianza IC: $0-36,9 \%$ t $6,9 \%$ con IC: $1,3 \%-19,3 \%$ respectivamente, siendo 3,6\% (IC: $0 .-18,8 \%$ ) los óbitos en el tercer trimestre (tabla 4).

De las gestantes con menos de 24 horas de enfermedades se hospitalizó el 27\% /7/26), pero lo hizo el $42 \%(5 / 12)$ y $44.4 \%(8 / 18)$ de pacientes con dos y tres días o mas de enfermedad (tabla 3). En las gestantes con dos días de enfermedad hubo un 16,7\%(2/12) de óbitos, y $11,1 \%(2 / 18)$ en pacientes con mas de 3 días. No hubo óbitos en las pacientes con menos de 24 horas de enfermedad (tabla 4).

Se hospitalizó el 33\% de pacientes con vómitos y dolor abdominal, el 59\% de gestantes con calambres y el $75 \%$ de las que tuvieron oliguria. El promedio de deposiciones diarias fue de 14.8 (SD 6.8) con un rango de 5 a 30. Se hospitalizó casi el 50\% de gestantes con más de 10 deposiciones diarias y el 66\% de las que tuvieron más de 20 deposiciones por día. De las 20 pacientes que llegaron al hospital con hipotensión arterial $45 \%$ requirió internamiento, y el $20 \%$ perdió el producto (tabla 5 ). De las 5 pacientes en las que se obitó el producto, cuatro presentaron hipotensión arterial. Ninguna de las pacientes hospitalizadas tuvo fiebre a su ingreso. 
Tabla No 5. Gestantes con cólera.

Caracteristicas clinicas por hospitalización

\begin{tabular}{|c|c|c|c|}
\hline & HOSPITALIZADAS & AMBULATORIAS & TOTAL \\
\hline VOMITOS & 20 & 40 & 60 \\
\hline DOLOR ABDOMINAL & 4 & 8 & 12 \\
\hline CALAMBRES & 10 & 11 & 27 \\
\hline $\begin{array}{l}\text { OLIGURIA } \\
\text { \# DEPOSICONES }\end{array}$ & $\boldsymbol{\theta}$ & 3 & 12 \\
\hline $\begin{array}{l}<10 \\
11-20 \\
>21\end{array}$ & $\begin{array}{r}4 \\
11 \\
4\end{array}$ & $\begin{array}{r}13 \\
12 \\
2\end{array}$ & $\begin{array}{r}17 \\
23 \\
6\end{array}$ \\
\hline HIPOTENSION ARTERIA & $\boldsymbol{\theta}$ & 11 & 20 \\
\hline
\end{tabular}

Se obtuvo el valor de creatinina sérica en 14 pacientes; el promedio fue de $1.5 \mathrm{mg} / \mathrm{dl}$, con un rango de 0.66 a $8.5 \mathrm{mg} / \mathrm{dl}$. Los niveles de creatinina eran mayores a $1 \mathrm{mg} / \mathrm{dl}$ en el $35,7 \%(5 / 14)$ de casos.

Una paciente desarrolló insuficiencia renal (creatinina de $8.5 \mathrm{mg} / \mathrm{dl}$ ), tenía depuración de creatinina de $4.12 \mathrm{cc} / \mathrm{min} / 1.73 \mathrm{~m}^{2}$, recuperándose sin necesidad de diálisis; la paciente tuvo un parto normal un mes después del episodio de cólera, obteniéndose un producto de 2,700 gramos de peso, adecuado para las 37 semanas de gestación.

Se obtuvieron datos referentes a la provisión de agua en 21 pacientes, la mitad de ellas o tenía servicio de agua en 21 pacientes, la mitad de ellas o tenía servicio de agua potable en su casa o éste era compartido, el 28,6\% compraba agua de camión y 19\% lo obtenía de pilón. Se interrogó a 15 pacientes con respecto a la eliminación de excretas, 6 tenían baño propio conectado al servicio de alcantarillado y 2 pacientes usaban baños compartidos, 6 pacientes usaban silo y una manifestaba eliminación de excretas en el campo.

Con respecto al tratamiento de las pacientes, que emplearon hidratación endovenosa, requirieron un promedio de 4.3 litros/día de solución salina fisiológica (cloruro de sodio al $0.9 \%$ en agua destilada), siendo el rango de 2 a 11 litros. De las pacientes con hidratación oral se empleó en promedio 1.4 litros día con un rango litros/día con un rango de 0.5 a 5 litros. Se administró antibióticos en 37 gestantes (44\%), siendo cloranfenicol el más utilizado $(92 \%)$.

\section{DISCUSIÓN}

El cólera, enfermedad de inusual presentación en América del Sur, ha producido en la presente epidemia graves consecuencias en la salud y economía de nuestra población.

Nuestro trabajo presenta la información hospitalaria y por lo tanto no representa los afectos de la epidemia en toda la población de mujeres gestantes de nuestra localidad, sin embargo creemos que es de interés, pues muestra las complicaciones más importantes de la enfermedad en nuestro medio.

El número total de gestantes con cólera que acudieron al hospital, representó menos del $1 \%$ de todos los pacientes con cólera atendidos en el hospital. En nuestra área 
hospitalaria el $4.7 \%$ de la población general son mujeres gestantes. Esta menor incidencia hospitalaria de cólera en gestantes podría tener varias explicaciones: pudiera ser que la mujer gestante tenga mayor resistencia a la deshidratación por el incremento fisiológico de su volumen plasmático; desde el punto de vista epidemiológico, pudiera haber tenido mayor precaución en evitar el contacto con personas infectadas y la ingesta de agua o alimentos contaminados; del punto de vista terapéutico, pudiera haber iniciado un tratamiento de rehidratación oral y antibióticoterapia temprana y por último hay la posibilidad que la gestante con cólera haya recibido tratamiento en los centros periféricos sin acudir al hospital.

Solo se obtuvo confirmación bacteriológica en el $8.3 \%$ de las gestantes, pero debemos recordar que nos encontramos en una epidemia de enfermedad diarreica aguda, en un medio de bajos recursos económicos, que obligó al hospital a limitar los estudios bacteriológicos a las primeras pacientes para diagnostica que la epidemia se trataba de cólera y una vez hecho esto se realizaron cultivos selectivos para corroborar la etiología y hacer estudios de sensibilidad antibiótica (7). Se obtuvo el $100 \%$ de positividad para Vibrio cholerae cepa El Tor variedad Inaba en los cultivos realizados. Creemos que el cuadro clínico característico, en estas circunstancias, fue suficiente para catalogar el cuadro de cólera y emprender el tratamiento respectivo (8).

Los reportes de las repercusiones del cólera en la mujer gestante y su producto son pocos, proviniendo la mayor parte de información del siglo pasado, de reportes de la década de 1950 o de estudios posteriores realizados en países asiáticos donde el cólera es endémico $(4,5,6)$. Las complicaciones maternas del cólera al igual que en la población general fueron básicamente consecuencia de las deshidratación, entre ellas shock hipovolémico, oliguria e insuficiencia renal. En nuestra serie, una gestante desarrolló insuficiencia renal y como menciona la literatura su recuperación no requirió diálisis (1). En nuestro estudio los cuadros con mayor severidad de cólera en gestantes se presentaron en las pacientes del segundo y tercer trimestre en igual proporción.

Sin embargo Hirschhorn (4) en Pakistán en 1969 menciona que las gestantes del tercer trimestre tienen un cuadro diarreico más severo comparado con gestantes del segundo trimestre y mujeres no gestantes (4).

Aparentemente la edad de la gestante fue también una variable que influyó en la severidad del cólera. Las gestantes menores de 20 años requirieron ser hospitalizadas en mayor proporción $(50 \%)$, y presentaron más pérdidas fetales $(30 \%)$ comparadas con los grupos etáreos. Esto pudiera atribuirse a un menor cuidado del embarazo y de los hábitos higiénicos-dietéticos en las jóvenes.

La mortalidad materna al igual que la mortalidad general era levada en el siglo pasado. Shultz reporta en la epidemia de 1892 en Alemania una mortalidad de 57\% en mujeres gestantes con cólera $(2,6,8)$. Sin embargo, la implementación de métodos adecuados y precoces de rehidratación oral y parenteral, ha permitido disminuir y prácticamente desaparecer la mortalidad materna por esta causa. Hirschhorn en su reporte, realizado en una zona endémica de cólera no mostró ninguna muerte materna en 60 pacientes (4). En nuestro hospital, en la presente epidemia, tampoco se ha registrado casos de muerte materna por cólera.

En el presente estudio las pérdidas fetales fueron mayores en el primer y segundo trimestre, lo cual concuerda con la literatura que menciona el desarrollo de abortos en la 
gestante con cólera (8). Hirschhorn reporta un porcentaje de abortos del segundo trimestre similar al nuestro, sin embargo describe una tasa mucho mayor que natimuertos $(50 \%)$ en el tercer trimestre.

Refiere además que esta complicación ocurre tempranamente en las primeras 24 horas de enfermedad, posiblemente debido a la hidratación precoz e intensiva. Por otro lado la ausencia de bacteremia en la madre sugiere que la muerte fetal no se deba a infección intrauterina. No se han encontrado reportes de malformaciones congénitas atribuibles a infección intrauterina por $V$. Cholerae (4).

El incremento de las pérdidas fetales en la mujer gestante con cólera obliga a buscar formas más efectivas de prevención en este grupo de riesgo $(4,5)$.

En la actualidad el uso de vacunas para el cólera no han demostrado un efecto epidemiológico favorable. Sin embargo el empleo de nuevas vacunas orales, aún es estudio, podría ser beneficioso $(1,3)$.

Los pacientes de nuestro hospital recibieron antibióticos, sobre todo en los casos con enfermedades corto tiempo, utilizándose con mayor frecuencia cloranfenicol. Se ha mostrado que el empleo de antibióticos en las primeras 24 horas de la enfermedad disminuye la severidad del cólera, lo cual podría atenuar los efectos en el feto $(1,4,8)$, sin embargo algunos reportes cuestionan este beneficio (1). El uso de profilaxis antibiótica en la población general o de riesgo o es considerado adecuado, pues no impide la propagación de la epidemia y conlleva la posibilidad de aparición de resistencia bacteriana (8). Los antibióticos recomendados en las gestantes son: ampicilina, cloranfenicol, furazolidona, sulfametoxazol-trimetropin y eritromcina $(1,8)$.

La presente epidemia en el Perú ha confirmado lo ya descrito en le siglo pasado, que la población está expuesta al riesgo de enfermar y morir sobre todo por falta de educación sanitaria y de instalaciones de agua potable y desagüe, situaciones comunes en la pobreza extrema o crítica, siendo pues imprescindible una reestructuración desde el punto de vista socio-económico, de salud pública y educación.

Este trabajo demuestra además, que el cólera en la gestante es un riesgo potencial de muerte fetal y que la atención precoz y adecuada debe disminuir la probabilidad de morbimortalidad materno-fetal por cólera. Por lo tanto es necesario educar a la población para que la mujer gestante con síntomas sugerentes de cólera acuda prontamente a un centro de salud para recibir hidratación y tratamiento antibiótico tempranos.

\section{Correspondencia:}

Dr. Pedro Saona Ugarte. Hospital Nacional Cayetano Heredia. Dpto. de Obstetricia y Ginecología. Av. Honorio Delgado s/n Lima 31, Perú.

\section{REFERENCIAS BIBLIOGRÁFICAS}

1.Greenough W. Vibrio cholerae. En: Principles and Practices of Infectious Diseases. Mandell GL, Douglas RG, Bannett J. John Willey and Sons, USA, 1985; 1208-1218. 2.Nalin D. Cholera. En: Hunter's Tropical Medicine. Strickland GT. W. Saunnders, USA, 1984; 305-312. 
3.Cabeza C, Huayanay L. El cólera, aspectos clínicos epidemiológicos y de control. Taller gráfico Neptuno. Lima, Perú. 1991.

4.Hirschhorn N, Allauddin A, Lindenbaum J. Cholera in pregnant Women. Lancet 969; 1: $1230-1232$.

5.Nesbitt R. Coincidental Medical Disorders Complicating Pregnancy. En: Textbook of Obstetrics and Gynecology. Danforth DN. Harper and Row, New York, USA, 1971, 432.

6.Williams Obstetrics. Eastman N. Appleton Century, New York, USA, 1960; 729.

7.Ministerio de Salud del Perú. Protocolo de Manejo Médico de los casos de cólera en establecimientos hospitalarios ESL/CCP/AGV/8 FEB. 1991.

8.Manson B, Bell DR. Manson's Tropical Disease Bailliere Tindall, Londres, 1987, 259-273. 